\section{Nuevas lecturas de La sombra del Caudillo, de Martín Luis Guzmán}

Alejandro Arteaga-Martínez

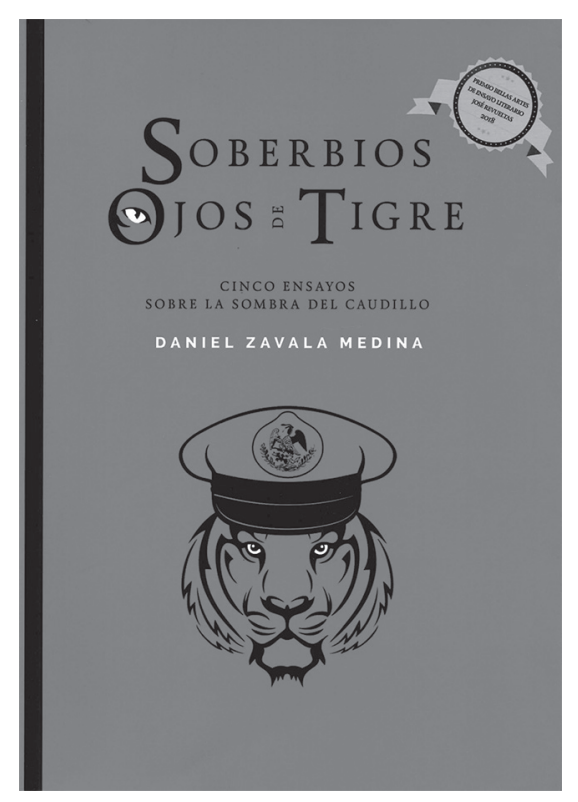

Daniel Zavala Medina, Soberbios ojos de tigre. Cinco ensayos sobre La sombra del Caudillo, ISBN 978-607-8409-72-3, Ciudad de México, Secretaría de Cultura / Instituto Nacional de Bellas Artes /

Textofilia, 2018, $111 \mathrm{pp.}$ i como decía Italo Calvino, un clásico es un libro que no termina de decir lo que tiene que decir, La sombra del Caudillo, de Martín Luis Guzmán, se nos presenta como un clásico de la literatura mexicana, pero quizá también de la universal. El reciente Premio Bellas Artes de Ensayo Literario 2018, Soberbios ojos de tigre..., de Daniel Zavala, demuestra la riqueza temática que aún queda por explorar en esa prodigiosa obra de Guzmán. En cinco breves ensayos, el investigador ofrece su lectura sobre la amistad, el ejercicio del poder, el cine y el petróleo en esta novela y, por último, su influencia en otras obras hispanoamericanas.

El primer ensayo, "Del teatro griego a «La película de la revolución»: Martín Luis Guzmán a 24 fotogramas por segundo", comienza recordando el interés del novelista por el cine, como demuestran las reseñas cinematográficas que publicó en España en 1915 y el proyecto fílmico titulado Islas Marías, novela y drama. Guion para una película, el cual nunca se llevó a cabo. A Zavala le interesan dos escenas de agilidad cinematográfica en las obras de Guzmán: el capítulo "La película de la revolución", de El águila y la serpiente, y la escena del "aterrador secuestro de Axkaná González y su viaje en vehículo, donde lo llevan vendado y tirado en el piso", de La sombra del Caudillo $(22)^{1}$.

De la primera escena, el investigador destaca la construcción de la improvisada sala de proyección a la que concurren varios revolucionarios, quienes ante las imágenes del odiado Carranza comienzan a dispararle sin saber que detrás del telón se esconden el narrador y algunos compañeros, que casualmente se libran de morir acribillados. Para Zavala, la escena es una metáfora de la historia: el narrador, que equipara con el propio Martín Luis Guzmán, es testigo privilegiado de los hilos que se entretejen en la revolución, la cual ve como si fuera una película que pasa ante sus ojos.

La segunda escena sorprende al investigador porque Axkaná hace una reconstrucción mental del recorrido hacia su destino mientras tiene vendados los ojos. El detalle con que describe la ciudad sobrepasa, a juicio del ensayista, el realismo decimonónico del que parte la obra de Guzmán, quien "logra trascenderlo de una forma inimaginada" (23). Esta reconstrucción es, además, una forma de evidenciar que

1 Todas las citas pertenecientes a Soberbios ojos de tigre. Cinco ensayos sobre La sombra del Caudillo corresponden a Zavala Medina, 2018, por lo cual sólo se anota el número de página. 
las fuerzas que acosan al cuerpo humano no pueden hacer nada contra la libertad de la imaginación.

El segundo ensayo, "Soberbios ojos de tigre: la bestia, el soberano, los rebaños”, indaga en los procesos de animalización que ocurren en La sombra del Caudillo y que, a juicio de Zavala, ofrecen una forma alternativa de entender el ejercicio del poder desde los conceptos de 'bios' y 'zoé'. Si bien el investigador advierte que no "son muchas las metáforas zoológicas en las páginas de esta [novela]” (31), las que están presentes le permiten una lectura enriquecedora de la obra de Guzmán.

Zavala parte de la metáfora más importante: el Caudillo —el presidente Álvaro Obregón - es un depredador. En consecuencia, quienes están a su alrededor le dan cacería o se convierten en sus presas. Siguiendo las ideas que Derrida expone en La bestia y el soberano, el ensayista propone la irresponsabilidad y la no-respuesta del gobernante frente a sus actos y a quienes afectan. Para Zavala Medina, la prueba de esta caracterización del Caudillo bestial está en el compromiso y contestación de algunas de sus víctimas, como Ignacio Aguirre, que nombra y compadece a sus compañeros de martirio.

Además de lo anterior, a Zavala le interesa el personaje de Catarino Ibáñez, próspero ganadero y gobernador del Estado de México. De acuerdo con el texto Formas comunes. Animalidad, cultura, biopolítica, de Gabriel Giorgi — quien estudia el espacio del matadero como lugar donde la vida animal es un mecanismo para aludir a las vidas del trabajador y a sus condiciones laborales-, Zavala considera los establos de Ibáñez como representación del poder biopolítico, pero de modo opuesto al matadero por su espectacular pulcritud y ausencia aparente de personas encargadas de cuidar a los animales. La extrema atención que Ibáñez brinda a su ganado contrasta con la ínfima valoración que su gobierno ofrece a las comunidades indígenas: la discriminación, la mala alimentación y el desdén con que las trata se justifica como una forma aceptable para 'ellos', que son diferentes al 'nosotros' de la clase política.

En "La amistad, una interpretación en clave aristotélica”, Zavala pasa revista a los vínculos predominantemente masculinos de La sombra del caudillo. El investigador recuerda que la crítica literaria ha leído la novela de Guzmán desde la tradición clásica, por lo que considera que "No debe juzgarse excesivo partir de la Ética a Nicómaco para estos comentarios sobre la novela mexicana" (56). Del tratado aristotélico, Zavala extrae los conceptos de amistad virtuosa, utilitaria, hedonista y por superioridad, los cuales ejemplifica con las relaciones de Remigio Tarabana (amistad utilitaria), Axkaná González (amistad hedonista) y el Caudillo (amistad por superioridad), así como con otros vínculos que le resultan menos claros 
de clasificar. Seguir de cerca estas relaciones permite comprobar los "elementos de evolución en diversos personajes [...] a partir de la amistad el narrador muestra distintos grados de trasformación de los personajes, reflejados en los cambios del tipo [de] relación que los une a lo largo de la novela" (62).

Para Zavala, en La sombra del Caudillo no hay amistades virtuosas, pues la política es un espacio de lucha constante por el poder y la dominación, como se observa en varios pasajes de la novela. Por esto, parece singular que el vínculo entre Ignacio Aguirre y Axkaná González, dos caracteres opuestos, sea "lo que produce el efecto placentero [de] la compañía y la conversación con el otro" (65), es decir, se trata de una amistad hedonista en el más clásico sentido aristotélico. En esta dirección, el investigador también comenta los guiños narrativos que llevan a pensar en una relación de tintes homoeróticos, lo cual hace que el lazo entre estos dos personajes contraste aún más en el repertorio de vínculos que estudia.

Quizá la delicadeza del lazo entre Aguirre y González explique bien lo que resulta peculiar para Zavala: la presencia de la Mora, una de las escasas mujeres en el mundo masculino de La sombra del Caudillo. Con base en Aristóteles, el investigador comenta que no puede haber una amistad entre hombres y mujeres. Sin embargo, el hecho de que, poniéndose en riesgo, la Mora aporte información útil para Aguirre y que incluso éste piense en considerarla una buena amiga, hace que Zavala cuestione la rigidez de la clasificación aristotélica. Su conclusión es que pese a los peligros a los que se expone, y precisamente por el desinterés ante los riesgos, estamos también ante un gesto de fraternidad desinteresada de una mujer hacia los dos hombres.

En "Oscuro dios mineral: dos capítulos sobre el petróleo en La sombra del caudillo", Zavala recuerda la compleja dinámica política con la que lidió el gobierno mexicano desde 1917 y hasta antes de la expropiación petrolera que llevó a cabo Lázaro Cárdenas. De esta delicada situación de la política internacional que se vivió tras la revolución surgió la llamada 'novela del petróleo': narrativas que abordaban los conflictos sociopolíticos alrededor del oro negro. Martín Luis Guzmán no fue ajeno a esta circunstancia, como demuestran algunos artículos periodísticos en los que fijó su defensa del petróleo como riqueza de la nación mexicana. El investigador recuerda los siete capítulos que Guzmán eliminó de la versión periodística de su novela al pasarla al formato de libro y considera que "El cheque de la «May-be»" y "Últimos días de un ministro" también eran prescindibles, pero se quedaron en la obra "porque ilustraban un significativo episodio sobre el petróleo y la corrupción en nuestro país" (89). 
El ensayo de Zavala no pretende vincular La sombra del Caudillo con la novela del petróleo, sino mostrar que la preocupación de Guzmán por la política mexicana en este ámbito quedó plasmada en ese par de capítulos donde se exponen los alcances de la corrupción. Con una fina perspicacia, el ensayista concluye que la anécdota del petróleo que ocupan aquellos dos apartados puede ubicarse cronológicamente: "podemos decir que la compra de favores al ministro de Guerra por parte de la May-be Petroleum Co. se dio, aproximadamente, en 1924. Es decir, durante la parte final del cuatrienio de Obregón. El cuatrienio de las «concesiones confirmatorias»" (93), mediante las cuales las empresas extranjeras tenían todavía derechos sobre el petróleo mexicano.

El último texto de Zavala, el más breve de los cinco, es un conjunto de notas sobre la "Presencia de La sombra del Caudillo en la narrativa mexicana contemporánea”. El autor pasa revista a algunos aspectos relacionados con la novela de Guzmán que aparecen en La muerte de Artemio Cruz, de Carlos Fuentes; El Jefe Máximo, de Ignacio Solares; La paz de los sepulcros, de Jorge Volpi; Tierra roja. La novela de Lázaro Cárdenas, de Pedro Ángel Palou; y Adiós muchachos, del nicaragüense Sergio Ramírez. Referencias y alusiones más hipertextuales que intertextuales son las formas en que se hace presente La sombra del Caudillo en ese repertorio de obras. No deja de ser interesante, por lo demás, que dos autores del Crack, Volpi y Palou, aparezcan en la revisión, así como las memorias sandinistas de Ramírez, en cuya edición del 2007 aparece un prefacio titulado como la novela de Guzmán.

Los ensayos que conforman Soberbios ojos de Tigre... son de extensión desigual: el primero y el quinto rondan las cinco o seis páginas, mientras que los centrales ocupan quince, veinte y veinticinco, respectivamente. Se trata de escritos de prosa ligera, tras la cual hay de fondo un sólido soporte teórico. Hay un equilibrio entre las ideas de Zavala y las de sus fuentes teóricas. Evidentemente, los cinco textos son producto de una profunda y detenida lectura de la obra, tanto literaria como periodística, de Martín Luis Guzmán.

Resultan de gran interés algunas notas del investigador en las cuales contrasta su análisis de la edición en libro de La sombra del Caudillo con la primera versión por entregas. El ensayista advierte que hubo construcciones de personajes que cambiaron en ambos documentos (así, el Axkaná González virtuoso de la novela ya no es el corrupto que apareció en las entregas periodísticas). Estas variaciones que Zavala va apuntando aquí y allá dejan al lector con la inquietud de que el ensayista optó por interpretar de cierta manera la novela de Guzmán. Ésta, en sus dos ediciones, sigue ofreciendo importantes lecturas que, como el ensayista propone, se enriquecen, 
por ejemplo, al estudiar la obra desde la tradición clásica o la biopolítica. Soberbios ojos de tigre... puede considerarse una amena invitación a releer La sombra del Caudillo, cuyos noventa años desde su publicación en 1929, en Madrid, se celebran en este 2019.

Alejandro Arteaga Martínez. Doctor en Letras por El Colegio de México (COLMEX), México. Profesor-investigador de tiempo completo en el campus San Lorenzo Tezonco de la Universidad Autónoma de la Ciudad de México (UACM), México. Entre sus publicaciones recientes se encuentran: "El teatro de José Dimayuga y la vida nueva" (Badebec. Revista del Centro de Teoría y Crítica Literaria, vol. 6, núm. 11); "Representaciones de la mujer migrante en cuentos mexicanos contemporáneos de Nadia Villafuerte y Liliana Pedroza" (iMex. México Interdisciplinario. Interdisciplinary Mexico, año 4, núm. 8); y "La figura femenina queer: querer ser mujer según Luis Zapata y Carlos Reyes Ávila”, en Mujeres, literatura y arte (BUAP, 2015). 